\title{
Spectrophotometric Quantitative Determination of Bromhexine Hydrochloride in Bulk and Pharmaceutical Dosage Form using PDEAB Reagent
}

\author{
K.SIDDAPPA* and PRASHANT C. HANAMSHETTY \\ Department of Studies and Research in Chemistry, Gulbarga University, \\ Gulbarga -585106, Karnataka, India \\ siddappa_65@rediffmail.com
}

Received 20 May 2016 / Accepted 4 June 2016

\begin{abstract}
An efficient, sensitive spectrophotometric method has been developed and validated for the determination of bromhexine hydrochloride (BRH), in bulk drug and its pharmaceutical formulations. The method is based on the formation of Schiff Base with paradiethylamminobenzaldehyde (PDEAB) the reaction of drug with reagent gives a bright yellow colour. The so formed coloured species absorbance was measured at its absorption maximum $\left(\lambda_{\max }\right)$ $425 \mathrm{~nm}$. The Beer's law has been obeyed in the concentration range $2-20 \mu \mathrm{g} / \mathrm{mL}$. The optical parameters were calculated as $2.42918 \times 10^{4} \mathrm{~L} / \mathrm{mol} / \mathrm{cm}, 0.016985 \mu \mathrm{g} / \mathrm{cm}^{2}$, molar absorptivity and Sandell's sensitivity respectively. The LOD and LOQ of the proposed method were calculated $0.2011 \mu \mathrm{g} / \mathrm{mL}, 0.6696 \mu \mathrm{g} / \mathrm{mL}$ respectively. All the variables were studied to optimize the reaction conditions. No interference was observed in the presence of common pharmaceutical excipients. The validity of the method was tested by analyzing BRH in its pharmaceutical formulations and critically tested for its accuracy by statistical tests. Good recoveries were obtained by the developed method; the obtained results were critically analyzed and successfully employed for the determination of $\mathrm{BRH}$ in its pharmaceutical dosage forms.
\end{abstract}

Keywords: Bromhexine, PDEAB, Spectrophotometry, Mucolytic agent, Schiff base, Validation

\section{Introduction}

Bromhexine $\mathrm{HCl}(\mathrm{BRH})$, chemically named 2-amino-3,5-dibromo- $N$-cyclohexyl- $N$-methyl benzenemethanamine hydrochloride (Figure 1), is a mucolytic agent used in the treatment of respiratory disorders associated with viscid or excessive mucus. This agent's mechanism is to increase the production of serous mucus in the respiratory tract and it makes the phlegm thinner and less viscous. BRH is a mucous modifying drug that helps to improve the flow properties of bronchial mucous and eases expectoration ${ }^{1,2}$. The drug is official in $\mathrm{IP}^{3}$ and $\mathrm{BP}^{4}$.

Because of its physiological importance, the drug has been quantified by exploiting its chemical $^{5,6}$ and physical properties ${ }^{7-25}$. The different analytical methods used to quantify the drug as a single active pharmaceutical ingredient include flow injection analysis with ion 
selective electrodes ${ }^{7}$, inductively coupled plasma mass spectrometry ${ }^{8}$, electrokinetic chromatography ${ }^{9}$, electrochemical oxidation at the glassy carbon electrode ${ }^{10}$, liquidchromatography ${ }^{11}$, liquid gas chromatography ${ }^{12}$, GC with mass detection ${ }^{13}$ and voltammetry ${ }^{14}$.

The drug has also been quantified in its combined formulations using HPLC ${ }^{15-18}$, direct and derivative UV spectrophotometry ${ }^{19-23}$. These methods involve scarcely available costly equipment and tedious experimentation.

Simple, accurate and precise methods using spectrophotometry have also been developed based on the production of chromophore by the interaction of the drug with an analytical reagent, as chromogen ${ }^{24-26}$. Availability of vast number of analytical reagents to serve as chromogens always leaves a lot of scope for pharmaceutical analysis. A thorough survey of the literature showed that the quantification methods of our interest are not reported yet and hence in the present communication we report a quantification method that has been developed and validated for quantification of bromhexine $\mathrm{HCl}$ both in pure and pharmaceutical dosage forms. In the present research work an effort has been made to develop and validate a simple spectrophotometric determination of BRH in bulk and pharmaceutical formulations. Although there are several highly sophisticated instrumental methods were reported but are suffered by time of analysis, cost per analysis, sophistication and most importantly the skilled analyst to handle the instruments. The present method offers a simple, sensitive, cost effective method for the determination of BRH in any common QC laboratory.<smiles>CN(Cc1cc(Br)cc(Br)c1N)C1CCC(O)CC1</smiles>

Figure 1. Chemical Structure of Bromhexine Hydrochloride

\section{Experimental}

Spectral and absorbance measurements were carried out by using double beam UVspectrophotometer ELICO-SL-244.

\section{Materials and reagents}

All the chemicals used were of analytical grade. All the solutions were prepared freshly and deionised water was used throughout the experiment. Ambroxol hydrochloride bulk drug obtained from sun pharmaceutical (Mumbai, India) certified to contain $99.5 \%$ of active ingredient, which has been used as a reference substance, as received without further purifications. Sublimed iodine was procured from Sd-Fine chemicals $99.5 \%$ purity and $\mathrm{HCl}$ procured from Sd-Fine chemicals 35\% purity. Methanol AR grade procured from Sd-Fine chemicals.

Bromhexine hydrochloride tablets were purchased from pharmaceutical store, different makes such as Ascoril ${ }^{\circledR}(8 \mathrm{mg} \mathrm{BRH})$ and TusQ ${ }^{\circledR}(8 \mathrm{mg} \mathrm{BRH})$ from Glenmark (India) laboratory Ltd. and Blue Cross Laboratory Ltd. respectively.

\section{Preparation of standard stock solution}

$10 \mathrm{mg}$ of the reference standard was accurately weighed and transferred in to a $10 \mathrm{~mL}$ volumetric flask, $5 \mathrm{~mL}$ of deionised water was swirled to mix and brought to the mark with deionised water. The apparent concentration has been reached to $1000 \mu \mathrm{g} / \mathrm{mL}$ further stepwise dilutions were made to obtain the working standard stock solution $100 \mu \mathrm{g} / \mathrm{mL}$. 


\section{Preparation of sample solution}

i) Ascoril ${ }^{\circledR}$ tablets (15 tablets) labelled claim to contain $8 \mathrm{mg}$ of BRH, average weight of each tablet was $420 \mathrm{mg}$ were triturated and made a fine powder, mixed it well for homogeneity. A portion $(5250 \mathrm{mg})$ of the fine powder was transferred to contain $100 \mathrm{mg}$ of the BRH in to a beaker and dissolved with $20 \mathrm{~mL}$ of deionised water and mixed well. This solution was filtered through a Whatmann filter paper No.41, in to a $100 \mathrm{~mL}$ volumetric flask. The filtrate was made up to the mark with deionised water.

ii) TusQ ${ }^{\circledR}$ tablets (15 tablets) labelled claim to contain $8 \mathrm{mg}$ of $\mathrm{BRH}$, average weight of each tablet was $550 \mathrm{mg}$ were triturated and made a fine powder, mixed it well for homogeneity. A portion $(6875 \mathrm{mg})$ of the fine powder was transferred to contain $100 \mathrm{mg}$ of the BRH in to a beaker and dissolved with $20 \mathrm{~mL}$ of deionised water and mixed well. This solution was filtered through a Whatmann filter paper No.41, in to a $100 \mathrm{~mL}$ volumetric flask. The filtrate was made up to the mark with deionised water.

\section{General procedure for the determination of bromhexine hydrochloride}

Variable aliquots of working standard solution containing 2-20 $\mu \mathrm{g} / \mathrm{mL}$ of BRH were transferred in to series $10 \mathrm{~mL}$ volumetric flasks. To each flask $1 \mathrm{~mL}$ of concentrated $\mathrm{HCl}$ was added, mixed the solution mechanically followed by added $2 \mathrm{~mL}$ of $2 \%$ PDEAB solution, heated the contents on water bath at $70^{\circ} \mathrm{C}$ for $5 \mathrm{~min}$ then there was the formation of yellow coloured Schiff base. The yellow coloured species absorbance was measured at $425 \mathrm{~nm}$ using reagent as a blank. The formation of Schiff base was shown in Scheme 1. The calibration graph was prepared by plotting absorbance versus concentration of drug and the concentration of unknown was read from the calibration graph or computed from the regression equation derived from the Beer's law data. The same procedure was followed for the determination of BRH in the tablet formulations and the content of the tablets were calculated by using regression equation.<smiles>CNC1CCC(O)CC1</smiles>

4-((2-amino-3,5-dibromobenzyl)(methyl)amino)cyclohexanol<smiles>CCN(CC)c1ccc(C=O)cc1</smiles>

4-(diethylamino)benzaldehyde $70^{\circ} \mathrm{C}$ for $5 \mathrm{~min} \mid-\mathrm{H}_{2} \mathrm{O}$<smiles>CCN(CC)c1ccc(C=Nc2c(Br)cc(Br)cc2CNC2CCC(O)CC2)cc1</smiles>

4-((3,5-dibromo-2-((4-(diethylamino)benzylidene)amino)benzyl)(methyl)amino)cyclohexanol

\section{Scheme 1}




\section{Results and Discussion}

Determination of absorption maxima $\left(\lambda_{\max }\right)$

To determine the $\lambda_{\max }$ of the coloured species, $1 \mathrm{~mL}$ of $100 \mu \mathrm{g} / \mathrm{mL}$ of the BRH was added to a $10 \mathrm{~mL}$ volumetric flask and $1 \mathrm{~mL}$ of concentrated $\mathrm{HCl}$, mixed the contents mechanically then added $2 \mathrm{~mL}$ of $2 \%$ PDEAB solution, heated the contents on water bath at $70{ }^{\circ} \mathrm{C}$ for $5 \mathrm{~min}$ then there was the formation of yellow coloured Schiff base. The flasks are allowed to cooled to room temperature and the solutions was made up to the mark with water. The coloured species was measured against reagent blank in the range of $350 \mathrm{~nm}$ to $900 \mathrm{~nm}$. The $\lambda_{\max }$ of the complex was found to be $425 \mathrm{~nm}$. Absorption spectrum of the proposed method was shown in Figure 2. Under the experimental conditions each reagent blank showed a negligible absorbance at the corresponding $\lambda_{\max }$.

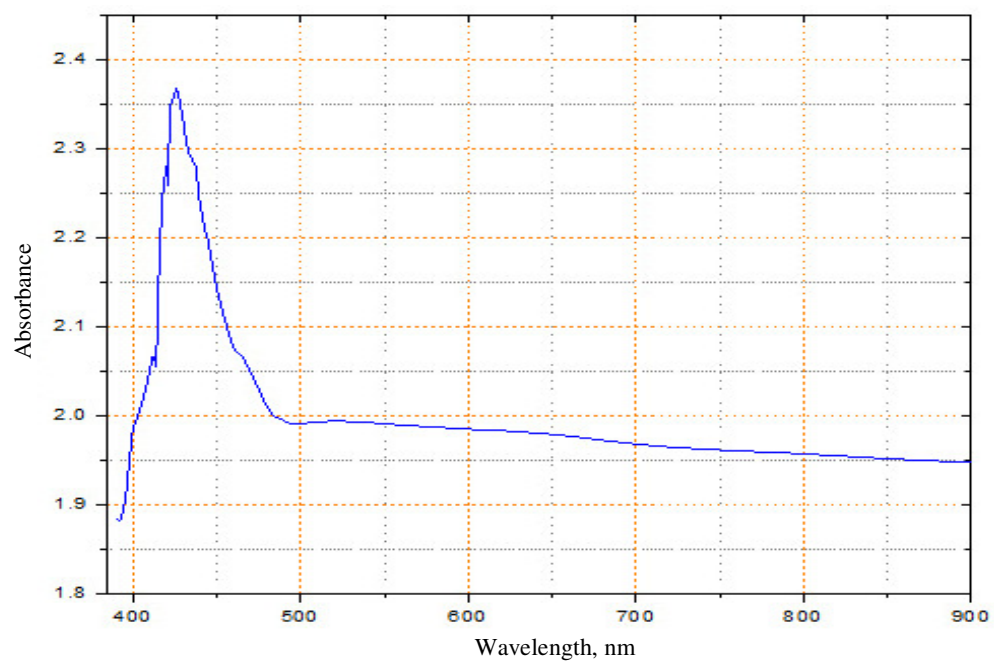

Figure 2. Absorption spectrum of the coloured species

\section{Investigation of assay parameters}

Optimum reagent concentrations required for the formation of sensitive and quantitative coloured products were determined by varying one reagent concentration and fixing the concentrations of other reagents and its effect on absorbance was measured at $425 \mathrm{~nm}$.

\section{Effect of heating time}

To study the effect of heating time for the development of maximum colour, the contents of the mixture were heated for up to $20 \mathrm{~min}$. at $70 \pm 1^{\circ} \mathrm{C}$. The intensity of the colour developed was measured at room temperature after the dilution to $10 \mathrm{~mL}$ with deionised water. It is apparent from the investigation that the maximum intensity of colour was obtained after $5 \mathrm{~min}$ of heating and remained constant. Therefore the optimum heating time was fixed to $5 \mathrm{~min}$.

\section{Effect of reagent concentration}

The effect of concentration of PDEAB solution and $\mathrm{HCl}$ were studied on the related absorbance values. Different concentrations of PDEAB solutions from $0.5 \%$ to $5 \%$ were studied. Volumes of $0.5-3.0 \mathrm{~mL}$ of PDEAB $(2 \%)$ and $0.5-3.0 \mathrm{~mL}$ of concentrated $\mathrm{HCl}$ were examined. The investigations showed that $2.0 \mathrm{~mL}$ of PDEAB and $1.0 \mathrm{~mL}$ of concentrated $\mathrm{HCl}$ 
gave maximum absorbance. There is no change in intensity of the colour any further with the increasing amounts of PDEAB and concentrated $\mathrm{HCl}$. So the $2.0 \mathrm{~mL}$ of PDEAB and $1.0 \mathrm{~mL}$ of concentrated $\mathrm{HCl}$ were chosen throughout the experiment.

\section{Interference studies}

To study the potential interference from the commonly used excipients and other additives such as glucose, lactose, starch, sodium starch glycolate, cellulose, magnesium stearate and ascorbic acid recovery studies were carried out. Under the experimental conditions employed, to a known amount of drug. The recovery studies suggest that there was no significant interference from the excipients on the assay of the drug.

\section{Validation of the method}

\section{Detection and quantification limits}

According to the analytical methods committee the detection limit (LOD) is the concentration of drug corresponding to a signal equal to the blank mean $\left(\mathrm{Y}_{\mathrm{B}}\right)$ plus three times the standard deviation of the blank $\left(S_{\mathrm{B}}\right)$. Quantification limit (LOQ) is the concentration of drug corresponds to the blank mean plus ten times the standard deviation of the blank. The LOD and LOQ values for BRH were found to be $0.2011 \mu \mathrm{g} / \mathrm{mL}$ and $0.6696 \mu \mathrm{g} / \mathrm{mL}$ respectively ${ }^{27}$.

\section{Quantification}

The optical characteristics such as Beer's law limits, Sandell's sensitivity and molar absorptivity were calculated for the proposed method and the results are summarized in Table 1. Regression analysis of the Beer's law plot at their $\lambda_{\max }$ revealed a good correlation as shown in Figure 3. For the regression analysis we have selected different concentration sets but the best fit curve was obtained in the concentration range 2 to $20 \mu \mathrm{g} / \mathrm{mL}$ of standard BRH. For the verification of Beer's law we have taken a series of $10 \mathrm{~mL}$ volumetric flasks and added the working standard solution $(100 \mu \mathrm{g} / \mathrm{mL})$ serially from $0.2 \mathrm{~mL}$ to $2.0 \mathrm{~mL}$ followed by added all the reagents as mentioned in the assay procedure. Graph of absorbance versus concentration plotted and are described by the regression equation $\mathrm{Y}=$ $\mathrm{bx}+\mathrm{a}$ (where ' $\mathrm{Y}$ ' is the absorbance, ' $\mathrm{b}$ ' is the slope, ' $\mathrm{x}$ ' is the concentration of the drug in $\mu \mathrm{g} / \mathrm{ml}$ and ' $\mathrm{a}$ ' is the intercept) obtained by least squares method ${ }^{28-30}$. The results were summarized in Table 1.

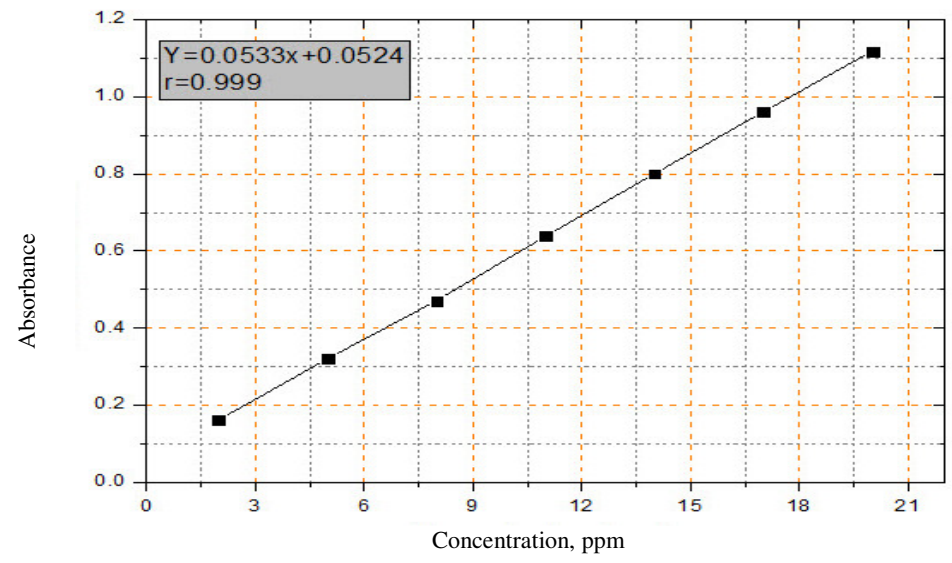

Figure 3. Beer's law calibration curve 
Table 1. Optical and regression characteristics, precision and accuracy of the proposed method

\begin{tabular}{cll}
\hline S. No. & \multicolumn{1}{c}{ Parameters } & \multicolumn{1}{c}{ Value } \\
\hline 1 & $\lambda_{\max }, \mathrm{nm}$ & 425 \\
2 & Beer's law limit, $\mu \mathrm{g} / \mathrm{mL}$ & $2-20$ \\
3 & Sandell sensitivity, $\mu \mathrm{g} / \mathrm{cm}^{2} / 0.001$ abs. unit & 0.016985 \\
4 & Molar absorptivity, $\mathrm{L}$ mole ${ }^{-1} . \mathrm{cm}^{-1}$ & $2.42918 \times 10^{4}$ \\
5 & Stability of color (hours) & 7 \\
6 & Regression equation & $\mathrm{y}=0.0533 \mathrm{x}+0.0524$ \\
7 & Correlation coefficient & 0.999 \\
8 & \% RSD & 0.7207 \\
9 & \% Range of errors & $0.471 \pm 0.0444 \times 10^{-3}$ \\
& $0.05 \%$ & $0.471 \pm 0.0341 \times 10^{-3}$ \\
& $0.01 \%$ & 0.2011 \\
10 & Limit of detection, $\mu \mathrm{g} / \mathrm{mL}$ & 0.6696 \\
\hline
\end{tabular}

\section{Accuracy precision and recovery studies}

The accuracy and precision of the proposed method was evaluated by performing five replicate determination of $\mathrm{BRH}$ in pure form at three different concentrations $(5,11$ and $17 \mu \mathrm{g} / \mathrm{mL}$ ) by short term (intra-day) precisions as shown in Table 2 . The standard analytical errors, relative standard deviations (\%RSD) and recoveries obtained in the intra-day analysis for the proposed method were found to be acceptable. Thus the proposed method is effective for the determination of BRH.

Table 2. Evaluation of the accuracy and precision of the proposed method by intra-day assay

\begin{tabular}{ccccc}
\hline \multicolumn{5}{c}{ Observed concentration of BRH, $\mu \mathrm{g} / \mathrm{mL}$} \\
\hline Concentration of & \multicolumn{4}{c}{ Intra-day } \\
\cline { 2 - 5 } BRH, $\mu \mathrm{g} / \mathrm{mL}$ & Mean* & Error, \% & RSD, \% & Recovery, \% \\
\hline 5 & 5.039 & 0.103 & 0.720 & 100.8 \\
11 & 10.96 & 0.063 & 0.222 & 99.63 \\
17 & 17.04 & 0.063 & 0.147 & 100.2 \\
\hline
\end{tabular}

*For five determinations

The accuracy of the proposed method was further checked by performing recovery experiments through standard addition technique. For this purpose, a known amount of pure $\mathrm{BRH}$ was added to pre-analyzed dosage forms and then determined by the recommended procedure. The results are as shown in Table 3. The values of mean recovery and relative standard deviation (\%RSD) were in the range of $99.75-99.98 \%$ and $0.207-0.301 \%$ respectively. This indicates the reproducibility of the method. No interference was observed from the common excipients of tablet.

\section{Applicability of the method}

The proposed method applied to the analysis of BRH in pharmaceutical dosage forms and the results were statistically compared with reference method by calculating the student's $t$-values. The evaluated $t$ - values were less than the tabulated values at the $95 \%$ confidence level for five degrees of freedom, as revealed by the results complied in Table 4. This actually suggests that the proposed method is accurate and precise as the reference method. 
Table 3. Determination of BRH in pharmaceutical formulation by standard addition technique

\begin{tabular}{cccccc}
\hline $\begin{array}{c}\text { Amount of } \\
\text { drug before } \\
\text { addition, } \mu \mathrm{g}\end{array}$ & $\begin{array}{c}\text { Amount of } \\
\text { drug added, }\end{array}$ & $\begin{array}{c}\text { Theoretical } \\
\text { amount, } \mu \mathrm{g}\end{array}$ & $\begin{array}{c}\text { Mean amount } \\
\text { recovered, } \mu \mathrm{g} \\
(\mathrm{n}=5)\end{array}$ & $\begin{array}{c}\text { Mean \% of } \\
\text { recovery } \\
(\mathrm{n}=5)\end{array}$ & RSD\% \\
\hline 5 & 5 & 10 & 9.974 & 99.76 & 0.242 \\
5 & 10 & 15 & 14.96 & 99.75 & 0.301 \\
5 & 15 & 20 & 19.99 & 99.98 & 0.207 \\
\hline
\end{tabular}

Table 4. Results of analysis of tablet formulation containing BRH

\begin{tabular}{cccccc}
\hline & \multicolumn{3}{c}{ \% Found \pm SD } \\
\hline Formulation & $\begin{array}{c}\text { Labeled } \\
\text { amount, mg }\end{array}$ & $\begin{array}{c}\text { Reference } \\
\text { method }^{\text {a }}\end{array}$ & $\begin{array}{c}\text { Proposed } \\
\text { method }\end{array}$ & $\begin{array}{c}\text { \%Recovery } \\
\text { of proposed } \\
\text { method }\end{array}$ & t-test $^{* *}$ \\
\hline Ascoril $^{\circledR}$ & 8 & 7.984 & $7.988 \pm 0.036$ & $99.85 \pm 0.60$ & 1.558 \\
TusQ $^{\circledR}$ & 8 & 7.032 & $99.78 \pm 0.57$ & 1.869 \\
\hline
\end{tabular}

*Recovery amount was the average of five determinations. ${ }^{* *}$ The $t$-value from table is 2.776 at $95 \%$ level. ' $a$ ' is the contents of BRH in reference method

\section{Conclusion}

The proposed method was quite simple and do not require any pre-treatment of the drug and tedious extraction procedure. The method has a wider range with good accuracy and precision. Hence, the data presented in the manuscript demonstrate that the proposed method was accurate, precise, linear, selective and offers advantages of reagent availability and stability, less time consumption and highly sensitive. Thus it can be extended for routine analysis of BRH in pharmaceutical industries and hospitals and research laboratories. Unlike the LC/MS procedure and HPLC procedures, the UV-Visible spectrophotometer instrument is simple and not of highly expensive on the other hand in simplicity and user friendly the method could be considered superior in comparison with the previously reported methods. Moreover the method is free from interferences by common additives and excipients.

\section{Acknowledgement}

The authors are grateful to Sun pharmaceuticals India Ltd. Mumbai for providing gift sample of reference grade BRH and also the Chairman of the Department of Chemistry, Gulbarga University, Gulbarga, for providing all facilities, support and encouragement to carry out the study. Authors are thankful to USIC Department Gulbarga University, Gulbarga, for necessary instrumentation help. One of the authors extends his sincere acknowledgment to the UGC for providing financial assistance in the form of BSR Fellowship (No.F.7-226/2009 (BSR) Dated: 06-08-2014).

\section{References}

1. Parvez L, Vaidya M, Sakhardande A, Subburaj S and Rajagopalan T G, Pulm Pharmacol Ther., 1996, 9(5-6), 299-308; DOI:10.1006/pulp.1996.0039

2. Cobbin D M, Elliott F M and Rebuck A S, Australian New Zealand J Med., 1971, 1(2), 137-140.

3. Indian Pharmacopoeia 1996 and Addendum 2000 (Government of India, Ministry of Health and Family welfare. Controller of publications. New Delhi, India). 
4. British Pharmacopoeia, vol. 2, HMSO, London, UK, 1996.

5. Zarapker S S, Rele R V and Doshi V J, Indian Dru., 1988, 26(1), 38.

6. Santoro M I R M, Dos Santos M M and Magalhaes J F, J AOAC Int., 1984, 67(3), 532-534.

7. Abdel-Ghani N T, Issa Y M and Ahmed H M, Sci Pharm., 2006, 74(3), 121-135; DOI:10.3797/scipharm.2006.74.121

8. Jensen B P, Gammelgaard B, Hansen S H and Andersen J V, J Anal At Spectrom., 2005, 20(3), 204-209; DOI:10.1039/B415003A

9. Okamoto H, Nakajima T, Ito Y, Aketo T, Shimada K and Yamato S, J Pharm Biomed Anal, 2005, 37(3), 517-528; http://dx.doi.org/10.1016/j.jpba.2004.11.011

10. Posp'́1silov'a M, Polasek M and Jokl V, J Pharm Biomed Anal. 2001, 24(3), 421-428; DOI:10.1016/j.jpba.2004.11.011

11. Rao E V, Rao G R, Raghuveer S and Khadgapathi P, Analyst, 1987, 112(6), 871-874; DOI:10.1039/AN9871200871

12. Lau O W and Cheung Y M, Analyst, 1990, 115(10), 1349-1353; DOI:10.1039/AN9901501349

13. Uboh C E, Rudy J A, Soma L R et al., J Pharm Biomed Anal., 1991, 9(1), 33-39; DOI:10.1016/0731-7085(91)80234-Z

14. Turch'an M, Jara-Ulloa P, Bollo S, Nũnez-Vergara L J, Squella J A and AlvarezLueje A, Talanta, 2007, 73(5), 913-919; DOI:10.1016/j.talanta.2007.05.010

15. Rauha J P, Salomies H and Aalto M, J Pharm Biomed Anal., 1996, 15(2), 287-293; DOI:10.1016/0731-7085(96)01846-8

16. Vasudevan M, Ravisankar S, George M and Ravi J, Indian Dru., 2000, 37(10), 489-492.

17. Dave H N, Mashru R C and Patel A K, J Pharm Sci Res., 2010, 2(3), 143-148.

18. El-Gindy A, Emara S and Shaaban H, J Pharm Biomed Anal., 2007, 43(3), 973-982; DOI:10.1016/j.jpba.2006.09.020

19. Gupta V, Verma M, Misra U and Nema R K, Asian J Chem., 2009, 21(2), 1633-1635.

20. Gupta A K and Kaskhedikar S G, Asian J Chem., 2003, 15(2), 977-980.

21. Panda S K, Sharma A K and Sahu L K, Indian J Pharm Sci., 2002, 64(6), 540-544.

22. Gangwal S and Trivedi P, Indian J Pharm Sci., 1999, 61(1-6), 128-131.

23. Song X, Wang X and Ze D, Zhongguo Yaoke Daxue Xuebao, 1999, 30(2), 100-102.

24. Mohan Rao S V M, Rao I N, Reddy T R S and Sastry C S P, Indian J Chem Tech., 2005, 12(2), 170-174.

25. Mohan Rao S V M, Prasad U V, Rao I N and Babu M S, Acta Cienc Indica, Chem 2004, 30(2), 105-108.

26. Babu S K, Ganapathi P A V, Raju N V S N and MadhuKumar G, Eastern Pharmacist, 1999, 42(493), 135-136.

27. International Conference on Harmonization ( $\mathrm{ICH})$ of Technical Requirement for the Registration of Pharmaceuticals for Human use, Validation of analytical procedures: definitions and Terminology Genera, 1996.

28. Siddappa K and Hanamshetty P C, Int J Pharm Sci Res., 2014, 5(10), 4188-4194; DOI:10.13040/IJPSR.0975-8232.5(10).4188-94

29. Siddappa K, Hanamshetty P C, Cur Pharm Anal., 2015, 11, 131.

30. Siddappa K and Hanamshetty P C, J App Pharm Sci., 2015, 5(3), 117-122. 